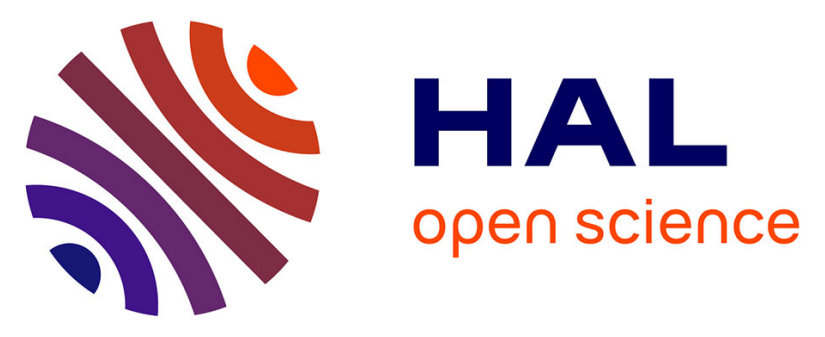

\title{
In Vitro Quantification of Mitral Regurgitation of Complex Geometry by the Modified Proximal Isovelocity Surface Area Method
}

Chloé Papolla, Jérome Adda, Arnaud Rique, Gilbert Habib, Régis Rieu

\section{To cite this version:}

Chloé Papolla, Jérome Adda, Arnaud Rique, Gilbert Habib, Régis Rieu. In Vitro Quantification of Mitral Regurgitation of Complex Geometry by the Modified Proximal Isovelocity Surface Area Method. Journal of The American Society of Echocardiography, 2020, 33 (7), pp.838-847.e1. 10.1016/j.echo.2020.03.008 . hal-03219410

\section{HAL Id: hal-03219410 \\ https://hal-amu.archives-ouvertes.fr/hal-03219410}

Submitted on 6 May 2021

HAL is a multi-disciplinary open access archive for the deposit and dissemination of scientific research documents, whether they are published or not. The documents may come from teaching and research institutions in France or abroad, or from public or private research centers.
L'archive ouverte pluridisciplinaire HAL, est destinée au dépôt et à la diffusion de documents scientifiques de niveau recherche, publiés ou non, émanant des établissements d'enseignement et de recherche français ou étrangers, des laboratoires publics ou privés.

\section{(1) (1) $\$$}

Distributed under a Creative Commons Attribution - NonCommercial - NoDerivatives 44.0 


\title{
In Vitro Quantification of Mitral Regurgitation of Complex Geometry by the Modified Proximal Isovelocity Surface Area Method
}

\author{
Chloé Papolla, MSc, Jérome Adda, MD, Arnaud Rique, MD, Gilbert Habib, MD, and Régis Rieu, PhD, Marseille, \\ Ollioules, and Aix-en-Provence, France
}

\begin{abstract}
Background: Doppler echocardiographic methods, such as the proximal isovelocity surface area (PISA) method, are used to quantify mitral regurgitations (MRs). However, their accuracy and reproducibility are still being discussed, especially in the case of MR of complex geometry. The aim of this study was to evaluate the accuracy of the PISA method depending on the shape and number of regurgitant flows.
\end{abstract}

Methods: First, various MR shapes and severities (central, oblong, and multiple-jet MR) were mimicked in a left heart simulator. The effective regurgitant orifice area (EROA) was calculated using the standard and modified PISA methods and was compared to a reference value obtained from an electromagnetic flowmeter. Second, in order to clinically validate the in vitro findings, 16 patients were examined with two-dimensional (2D) echocardiography. The results were analyzed by comparing the PISA method and the echocardiographic 2D quantitative volumetric method.

Results: Both hemicylindrical and hemiellipsoidal PISA assumptions improved the quantification of the EROA for oblong MR compared with the traditional PISA method (hemispherical PISA assumption: $11 \pm 4.6 \mathrm{~mm}^{2}$, $P<.01$; hemicylindrical PISA assumption: $2 \pm 0.8 \mathrm{~mm}^{2}, P=.83$; hemiellipsoidal PISA assumption: $\left.6 \pm 3.7 \mathrm{~mm}^{2}, P=.05\right)$. In the case of multiple jets of different sizes, an improved EROA calculation was measured when both jets were considered (single hemispherical PISA assumption: $4.5 \pm 0.7 \mathrm{~mm}^{2}, P<.01$; double hemispherical PISA assumption: $2 \pm 1.1 \mathrm{~mm}^{2}, P=.64$ ).

Conclusion: For a correct diagnosis of MR, the PISA geometry must be considered. A measurement of both PISA radius and PISA width is necessary for an accurate quantification of an oblong MR. In the case of a double-jet MR, a measurement of the two radii is recommended. (J Am Soc Echocardiogr 2020;33:838-47.)

Keywords: Proximal isovelocity surface area, Mitral regurgitation quantification, Secondary mitral regurgitation, Multiple regurgitant orifices, 2D Doppler echocardiography

Mitral insufficiency is a frequent pathology affecting roughly $9 \%$ of the elderly population in industrialized countries. ${ }^{1}$ An accurate mitral regurgitation (MR) quantification is essential for an accurate diagnosis of the insufficiency severity and appropriate clinical decision. ${ }^{2}$ According to

From the Aix-Marseille University, Gustave Eiffel University (C.P., R.R.), Marseille; Department of Cardiology, Polyclinique les Fleurs (J.A.), Ollioules; Cardiology Department, APHM, La Timone Hospital (A.R., G.H.), and Aix-Marseille University, IRD, APHM, MEPHI, IHU-Méditerranée Infection (A.R., G.H.), Marseille; and Képhalios, Part of Affluent Medical Group (C.P.), Aix-en-Provence, France.

Drs. Papolla and Adda contributed equally to this work and are co-first authors.

Conflicts of Interest: None.

Reprint requests: Professor Gilbert Habib, Cardiology Department, La Timone Hospital, Boulevard Jean Moulin, 13005 Marseille, France (E-mail: gilbert. habib3@gmail.com).

0894-7317/ $\$ 36.00$

Copyright 2020 by the American Society of Echocardiography.

https://doi.org/10.1016/j.echo.2020.03.008 the European and the American guidelines, the main method to quantify MR is the proximal isovelocity surface area (PISA) method. ${ }^{3,4}$ In primary MR, the threshold to define MR as severe is $40 \mathrm{~mm}^{2}$ for the effective regurgitant orifice area (EROA) and $60 \mathrm{~mL}$ for the regurgitant volume (RVol). However, this threshold is still debated in secondary $M R$, in which the regurgitant orifice is frequently elliptical and therefore an accurate quantification is more difficult. If lower thresholds are accepted $\left(20 \mathrm{~mm}^{2}\right.$ for the EROA, $40 \mathrm{~mL}$ for the RVol), they may lack specificity. In the era of interventional treatments for secondary $\mathrm{MR}$, a precise quantification is therefore crucial, as the outcomes are dependent, among other parameters, on the RVol. ${ }^{5,6}$ In the case of a round orifice, the calculation of the EROA is simple and reliable. ${ }^{7,8}$ However, for an elliptical orifice, the PISA method may underestimate by $25 \%$ the effective RVol, mainly because it only considers the smaller radius of a crescent-shaped regurgitant flow. ${ }^{9-12}$ Furthermore, there is currently no recommendation for a double regurgitant orifice MR quantification. ${ }^{3,4}$ Studies have shown that a modification in the PISA method formula may allow a correction of the measurement. These modifications could be either a multiplane evaluation of the PISA shape 


\section{Abbreviations}

2D = Two-dimensional

3D = Three-dimensional

AO $=$ Aorta

$\mathbf{C W}=$ Continuous wave

EROA = Effective regurgitant orifice area

EROA_2DQV = Effective regurgitant orifice area calculated with the echographic quantitative volumetric method

EROA_FM = Effective regurgitant orifice area determined with the flowmeter

EROA_PISA = Effective regurgitant orifice area determined with the proximal isovelocity surface area method

$\mathbf{L A}=$ Left atrium

$\mathbf{L V}=$ Left ventricle

$\mathbf{M R}=$ Mitral regurgitation

MV = Mitral valve

PISA = Proximal isovelocity surface area

RVol = Regurgitant volume

RVol_2DQV = Regurgitant volume calculated with the two-dimensional echographic quantitative volumetric method

RVol_FM = Regurgitant volume measured with the flowmeter

RVol_PISA = Regurgitant volume calculated with the PISA method

TEE $=$ Transesophageal echocardiography

VTI = Velocity-time integral

, $L A$ and $A O$ pressures were eters (Millar MPR 500, Millar Sensor System Solution, Houston, TX accuracy range, $\pm 0.5 \% ;-50$ to $300 \mathrm{~mm} \mathrm{Hg}$ ), precalibrated in a water column. The diastolic and systolic flow volumes were measured using an electromagnetic flowmeter (Probe 95, Carolina Medical, East Bend, NC, internal diameter $30 \mathrm{~mm}$, accuracy $\pm 2 \mathrm{~mL} /$ minute). It was positioned between LA and LV, upstream of the mitral valve (MV) to measure the total RVol (RVol_FM), calculated as the integral of the backward flow volume (sum of closing and RVols). To maximize the accuracy, measurements were recorded during 100 consecutive cardiac cycles and then averaged.

\section{MR Models}

A total of five geometries of MR were simulated, allowing measurements of several RVols by varying the flow rate. Thirteen MRs were simulated from a circular orifice in a rigid plate, $14 \mathrm{MRs}$ from a central orifice in a bioprosthesis, $12 \mathrm{MRs}$ from an oblong orifice in a bioprosthesis, $10 \mathrm{MRs}$ of two jets in a rigid plate, and $10 \mathrm{MRs}$ of two jets in an anatomically shaped MV made of hydrogel.

First, in order to validate our measurement methods, circular orifices were designed on rigid plates. Two rigid plates with a single orifice were designed, one with a geometric orifice area of $28 \mathrm{~mm}^{2}$ and the other of $78 \mathrm{~mm}^{2}$. The double orifice plate was designed with two circular holes, with a center to center distance of $15 \mathrm{~mm}$ and a geometric area of $28 \mathrm{~mm}^{2}$ and $12 \mathrm{~mm}^{2}$. Second, to allow a physiologic LV filling, a central and an oblong MR were mimicked on a mitral bioprosthesis. The bioprosthesis leaflets were sutured to the annulus in a semiopen position, creating a central regurgitation. In a second set of experiments, the sutures were moved to obtain an elliptical orifice (Figure $1 \mathrm{C}$ ). Finally, an anatomically shaped mitral MV made of hydrogel was designed and manufactured for this study (LifeLike BioTissue, London, ON, Canada). This valve has six chordae and presents tactile and mechanical properties of human tissue. An anteroposterior suture was made on the central part of the leaflets according to the Alfieri technique (i.e., between the A2 and P2 mitral leaflets; Figure 1 C). ${ }^{18}$ The double orifice MR was then created by applying a calibrated strain on the chordae. The chordae were passed through the ventricle lateral walls and then were directed into catheters fixed on introducers (Radifocus Fr. 6) positioned on the ventricular activation chamber. Once out of the box, the chordae were fixed to adjust their tension. Hemodynamic performance of this valve has been studied and is described in Supplemental Material 1.

\section{Quantification of MR}

For this study, a watertight opening was added to the LV box to introduce a transesophageal echocardiography (TEE) probe Echographic measurements were acquired with a General Electric Vivid 7 system (General Electric Medical Systems, Horten, Norway) using a TEE probe (6Tc-RS TEE probe, $5.0 \mathrm{MHz}$ ) and a Philips EPIQ7 ultrasound system with a X7-2t TEE probe (Philips Medical Systems, The Netherlands). To minimize the distance between the valve and the TEE probe, the latter was placed directly in the LV box within a distance of $1 \mathrm{~cm}$ from the apex and $8 \mathrm{~cm}$ from the MV.

The EROA determined using the flowmeter (EROA_FM) was calculated as the ratio of the RVol directly measured from the flowmeter and the velocity-time integral (VTI) of the regurgitant jet obtained with echocardiography (EROA_FM $=$ RVol_FM/VTI). Ten PISA radii, chosen from the best-quality images selected from four registered cardiac cycles, were measured and averaged. The RVol_PISA was determined us ing the PISA method, RVol_PISA = EROA_PISA * VTI, EROA_PISA $=$ PISA_S assumption ${ }^{*} V_{a} / V_{\text {max }}$. PISA_S assumption was the PISA area calculation according to the assumption made on PISA geometry; VTI and maximal peak velocity $\left(V_{\max }\right)$ were obtained by continuous-wave Doppler acquisitions by tracing the contour of the regurgitant jet; $V_{a}$ was the aliasing velocity (fixed between 20 and $40 \mathrm{~cm} /$ sec to obtain an optimal PISA shape).

For each type of MR, EROA_PISA and RVol_PISA calculated using the appropriate assumption of the PISA method were compared to EROA_FM and RVol_FM. For the central MR, mimicked on a rigid plate and a bioprosthetic valve, one echographic plane was acquired at the center of the regurgitant orifice to measure the PISA radius $(r$ 

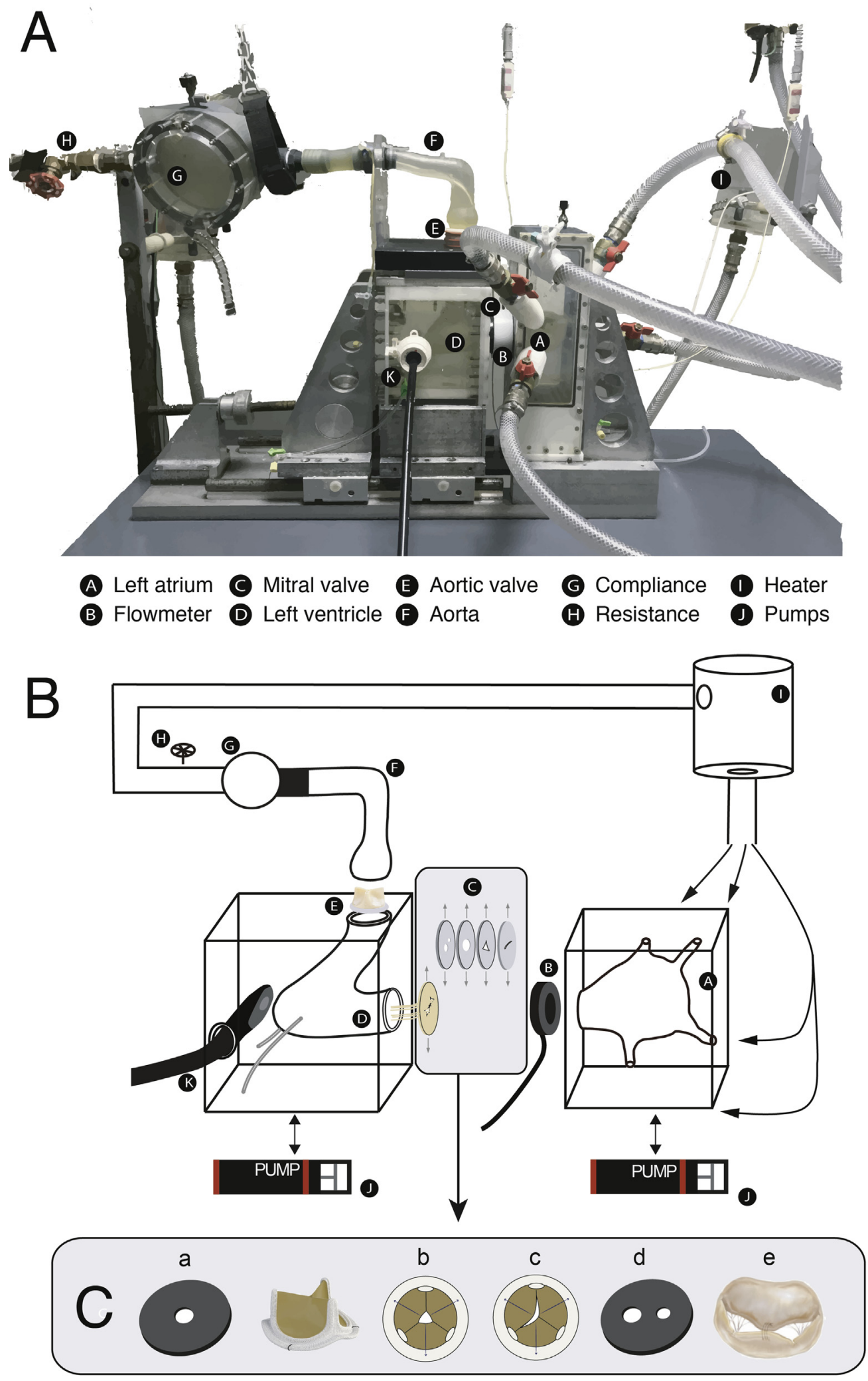

Figure 1 (A) Image of the double-activation simulator. (B) Schematic of the experimental setup. (C) Mimicked MVs. (a) Single circular orifice in a rigid plate, (b) central orifice in a bioprosthesis, (c) oblong orifice in a bioprosthesis, (d) two circular orifices in a rigid plate, (e) two orifices in an anatomical MV. 


\section{HIGHLIGHTS}

- Adjust the PISA assumptions to the type of mitral regurgitation encountered.

- Consider the width and radius of the PISA to quantify functional mitral regurgitation.

- To quantify double-jets mitral regurgitation, both PISA should be considered.

Figure 2A). EROA_PISA and RVol_PISA were calculated using the hemispherical assumption (PISA_S $S_{\text {hemispherical }}=2 \pi r^{2}$ ).

For the functional MR, an oblong PISA geometry was considered. Three assumptions made on the PISA shape were compared. First, the traditional PISA was calculated using PISA_S $S_{\text {hemispherical. Second, the }}$ PISA shape was considered to be hemicylindrical. The measurements of PISA radius ( $r$ ) and PISA width ( $W$; Figure $2 \mathrm{~B}$ ) were acquired on two orthogonal echographic planes of the orifice. The first plane was obtained in the apical long axial view, and the second plane by turning the probe by $90^{\circ}$. EROA_PISA and RVol_PISA were calculated using PISA_S $S_{\text {hemispherical }}=\pi r(r+W)$. Finally, the PISA shape was considered as hemiellipsoidal. EROA_PISA and RVol_PISA were calculated using

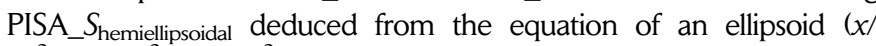
$A)^{2}+(y / B)^{2}+\left(z / C^{2}=1\right.$, where $A$ was the radius in the $x$-axis, $B$ was the radius in the $y$-axis, and $C$ was the radius in the $z$-axis. ${ }^{19}$ We considered the shape as hemiellipsoidal revolved around the $x$ axis (with $x$ following the flow direction). A simplified equation of the hemiellipsoidal area was calculated, PISA_S hemiellipsoidal $=\pi B\left(B+A^{2} / \mathrm{sqrt}\left(B^{2}-A^{2}\right){ }^{*} \ln \left(B+\left(B^{2}-\right.\right.\right.$ $\left.A^{2}\right) / A$ ), where $A$ was the PISA radius on the $x$-axis, $B$ was the PISA half-width of the orifice in $y$-and $z$-axes, and $\ln$ is the natural logarithm.

In the case of multiple-jet MR, an echographic plane allowing the visualization of the two convergence zones was acquired. First, EROA_PISA and RVol_PISA were estimated using PISA_ $S_{\text {Single-hemisphere }}=2 \pi r_{1}^{2}$ with $r_{1}$ as the biggest PISA radius. Second, PISA radii of both convergence zones were added to calculate PISA_S $S_{\text {Double-hemisphere }}=2 \pi r_{1}^{2}+2 \pi r_{2}^{2}$, with $r_{1}$ and $r_{2}$ as both PISA radii.

\section{Hemodynamics Conditions}

For all experiments, the pulse duplicator was used to simulate a heart rate of $60 \mathrm{bpm}$, the mean aortic pressure was fixed at
$100 \mathrm{~mm} \mathrm{Hg}$, and cardiac outputs, calculated as the positive portion of flow, varied from 2 to $5.5 \mathrm{~L} /$ minutes.

\section{In Vivo Investigation}

Study Population. Sixteen echocardiograms of patients with oblong or multiple jets of MR were retrospectively analyzed in this study. Thirteen patients had an oblong MR, and three had a multiple-jet MR. Patient characteristics including echocardiographic measurements are shown in Table 1.

Echocardiographic Acquisitions. Two-dimensional (2D) echocardiographic examination was performed with a Vivid E95 GE system (General Electric Medical Systems, Horten, Norway) equipped with a $10-4 \mathrm{MHz}$ M5Sc-D TTE transducer. A comprehensive evaluation including assessing the shape of the regurgitant orifice and the mechanism of the MR was performed from the parasternal and apical views, to determine the formula that should be applied. The LV dimensions and ejection fraction were calculated with the biplane Simpson method. The quantitative volumetric method was considered as the clinical reference to calculate the EROA_2DQV (2D echographic quantitative volumetric method) and the RVol_2DQV. The total LV stroke volume was calculated as the difference between the enddiastolic and end-systolic volumes from the biplane Simpson method and the aortic stroke volume as the product of the left ventricular outflow tract area and aortic VTI. The RVol_2DQV was inferred as the difference between the total stroke volume and the aortic stroke volume. The EROA_PISA and RVol_PISA were calculated as previously described for the in vitro experimentations.

Interobserver and Intraobserver Variability. The interobserver variability of the different PISA methods was evaluated independently by two cardiologists in 10 patients. The intraobserver variability was calculated in four patients.

\section{Statistics}

Statistical analysis was performed using SPSS (IBM Corp. released 2013, ver. 22.0. Armonk, NY). Continuous variables were expressed as mean $\pm \mathrm{SD}$. Comparisons of the mean EROA for different assumptions were performed with a paired $t$ test. Linear regression and Bland-Altman bias with limits of agreement were performed to estimate the precision of the different methods. Differences were considered significant when $P<.05$. Due to the low number of patients $(n=3)$ included in vivo for the double-jet MR, no statistical
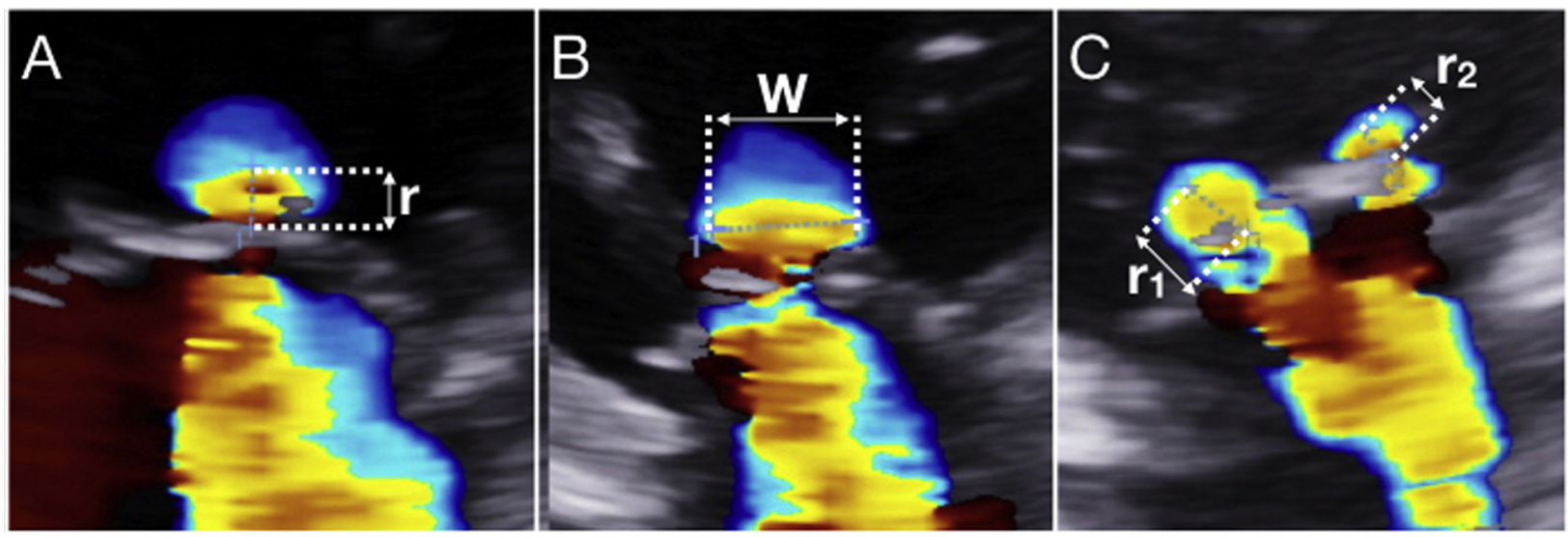

Figure 2 Illustration of a 2D color Doppler acquisitions used for a (A) representation of the PISA radius $(r)$, (B) representation of the PISA width $(W)$ in the case of functional MR, and $(C)$ representation of the two radii $\left(r_{1}, r_{2}\right)$ measured in the case of a multiple-jet MR. 
Table 1 Baseline characteristics of patients

\begin{tabular}{lc}
\hline \multicolumn{1}{c}{ Variables } & Values $(\boldsymbol{N}=\mathbf{1 6})$ \\
\hline Patients characteristics: & \\
\hline Age, years & $65 \pm 18$ \\
\hline Body surface area, $\mathrm{m}^{2}$ & $1.8 \pm 0.2$ \\
\hline Echographic variables: & $49 \pm 17$ \\
\hline LV ejection fraction, $\%$ & $266 \pm 100$ \\
LV end-diastolic volume, $\mathrm{mL}$ & $146 \pm 89$ \\
LV end-systolic volume, $\mathrm{mL}$ & $145 \pm 51$ \\
\hline LV end-diastolic volume index, $\mathrm{mL} / \mathrm{m}^{2}$ & $79 \pm 45$ \\
\hline LV end-systolic volume index, $\mathrm{mL} / \mathrm{m}^{2}$ & $219 \pm 68$ \\
Mean aortic flow, $\mathrm{mL} / \mathrm{sec}$ & $120 \pm 33$ \\
\hline Stroke volume, $\mathrm{mL}$ & $60 \pm 21$ \\
\hline Stroke volume index, $\mathrm{mL} / \mathrm{m}^{2}$ &
\end{tabular}

Data are expressed as mean \pm SD.

analysis was provided. Interobserver and intraobserver variability were quantified by the Bland-Altman bias with limits of agreements and by the coefficients of variation and correlation.

\section{RESULTS}

\section{Experimental Study}

Table 2 summarizes the values of RVol and EROA given by the PISA method and the flowmeter measurements from in vitro experiments.

In the case of a single central and circular orifice mimicked in a rigid plate, the calculated EROA_PISA using the hemispherical assumption correlated well with the EROA_FM $(r=0.99, P<.01)$ without significant bias $\left(-0.1 \pm 1.4 \mathrm{~mm}^{2}, P=.71\right)$ and an absolute error of $0.5 \pm 0.5 \mathrm{~mm}^{2}(P=.98)$.

The central orifice regurgitant jet in the bioprosthesis was quantified using the hemispherical assumption (Figure 3). The EROA_PISA had an excellent correlation with the EROA_FM ( $r=0.96, P<.01)$, with no significant bias $\left(-1.7 \pm 10.5 \mathrm{~mm}^{2}\right.$, $P=.28)$ and no significant absolute error $\left(4.9 \pm 2.4 \mathrm{~mm}^{2}, P=.19\right)$.

In the setting of an oblong MR, three assumptions were tested: the classic method with the hemispherical PISA, the hemicylindrical, and the hemiellipsoidal modified PISAs (Figure 4). Using the hemispherical PISA assumption, the EROA_PISA correlated well with the
EROA_FM $(r=0.97, P<.01)$ but led to a significant underestimation of $44 \% \pm 12 \%$ (bias, $-10.6 \pm 8.9 \mathrm{~mm}^{2}, P<.01$ ) with a significant absolute error of $10.6 \pm 4.6 \mathrm{~mm}^{2}, P<.01$. The EROA_PISA and EROA_FM calculated using the hemicylindrical assumption had an excellent correlation $(r=0.98, P<.01)$, with no significant underestimation (bias, $0.1 \pm 3.6 \mathrm{~mm}^{2}, P=.93$ ) and an absolute error of $2 \pm 0.8 \mathrm{~mm}^{2}(P=.83)$. The quantification of the EROA_PISA with the hemiellipsoidal assumption correlated also well with the EROA_FM $(r=0.90, P<.01)$, with a slight underestimation (bias, $\left.-5.2 \pm 10.3 \mathrm{~mm}^{2}, P=.01\right)$ and an absolute error of $6 \pm 3.7 \mathrm{~mm}^{2}(P=.05)$.

Double regurgitant orifice MR was first simulated in a rigid plate and quantified using both the single and double hemispherical PISA as sumptions. The EROA_PISA obtained with the single hemispheric PISA assumption correlated well with the EROA_FM $(r=0.99$, $P<.01$ ). However, a significant underestimation of $24 \% \pm 7 \%$ of the EROA_PISA was observed (bias, $-5.6 \pm 2.0 \mathrm{~mm}^{2}, P<.01$ ) with a significant absolute error of $5.6 \pm 3.9 \mathrm{~mm}^{2}(P<.01)$. The EROA_PISA obtained with the double hemispherical PISA assumption showed an excellent correlation with the EROA_FM $(r=0.99$ $P<.01)$ and had neither a significant bias $\left(-0.4 \pm 3.7 \mathrm{~mm}^{2}\right.$, $P=.57)$ nor a significant absolute error $\left(1.4 \pm 1.2 \mathrm{~mm}^{2}, P=.64\right)$

MR with double jets was then simulated in anatomically shaped MV (Figure 5). The EROA_PISA obtained with the single hemispherical PISA assumption correlated with the EROA_FM $(r=0.99, P<.01)$. As observed previously on the rigid plate, a significant underestimation was observed (bias, $-4.5 \pm 1.3 \mathrm{~mm}^{2}, P<.01$ ) with a significant absolute error of $4.5 \pm 0.7 \mathrm{~mm}^{2}, P<.01$ ). The EROA_PISA obtained with the double hemispherical PISA assumption correlated well with the EROA_FM $(r=0.99, P<.01)$ with no significant bias (bias, $\left.-0.4 \pm 4.7 \mathrm{~mm}^{2}, P=.64\right)$ and no significant absolute error $\left(2.0 \pm 1.1 \mathrm{~mm}^{2}, P=.50\right)$.

\section{Clinical Study}

Clinical data are summarized in Table 3. Functional MR was quantified with the hemispherical, hemicylindrical, and hemiellipsoidal assumptions and compared to the EROA and RVol obtained by the 2D quantitative volumetric method (Figure 6). The hemispherical PISA assumption showed a good correlation for EROA_PISA and EROA_2DQV $(r=0.90, P=.04)$. However, the EROA_PISA was underestimated compared with the EROA_2DQV (bias, $-11.3 \pm 26.6 \mathrm{~mm}^{2}, P<.01$ ), with a significant absolute error of $13.1 \pm 22.8 \mathrm{~mm}^{2}, P=.01$. The EROA_PISA calculated using the hemicylindrical PISA assumption

Table 2 Average values from in vitro experiments of RVol and EROA given by PISA method and flowmeter measurements

\begin{tabular}{|c|c|c|c|c|c|c|}
\hline PISA assumption & EROA_FM & EROA_PISA & $P$ value & RVol_FM & RVol_PISA & $P$ value \\
\hline \multicolumn{7}{|l|}{ Central MR } \\
\hline Hemispherical & $22.0 \pm 19.5$ & $23.9 \pm 16.1$ & .18 & $31.9 \pm 21.7$ & $35.1 \pm 16.1$ & .11 \\
\hline \multicolumn{7}{|l|}{ Oblong MR } \\
\hline Hemispherical & $25.5 \pm 11.3$ & $14.8 \pm 7.0$ & $<.01$ & $44.0 \pm 19.8$ & $25.6 \pm 12.6$ & $<.01$ \\
\hline Hemicylindrical & $25.5 \pm 11.3$ & $25.5 \pm 10.5$ & .83 & $44.0 \pm 19.8$ & $43.8 \pm 18.9$ & .85 \\
\hline Hemiellipsoidal & $25.5 \pm 11.3$ & $20.2 \pm 6.8$ & .55 & $44.0 \pm 19.8$ & $45.9 \pm 22.1$ & .39 \\
\hline \multicolumn{7}{|l|}{ Double-jet MR } \\
\hline Hemispherical & $15.6 \pm 5.6$ & $11.0 \pm 5.12$ & $<.01$ & $37.3 \pm 19.0$ & $26.5 \pm 16.4$ & $<.01$ \\
\hline Double hemispherical & $15.6 \pm 5.6$ & $15.2 \pm 7.42$ & .64 & $37.3 \pm 19.0$ & $38.5 \pm 24.3$ & .50 \\
\hline
\end{tabular}

Data are shown as mean \pm SD. EROA is in units of $\mathrm{mm}^{2}$, and RVol is in units of $\mathrm{mL}$. 

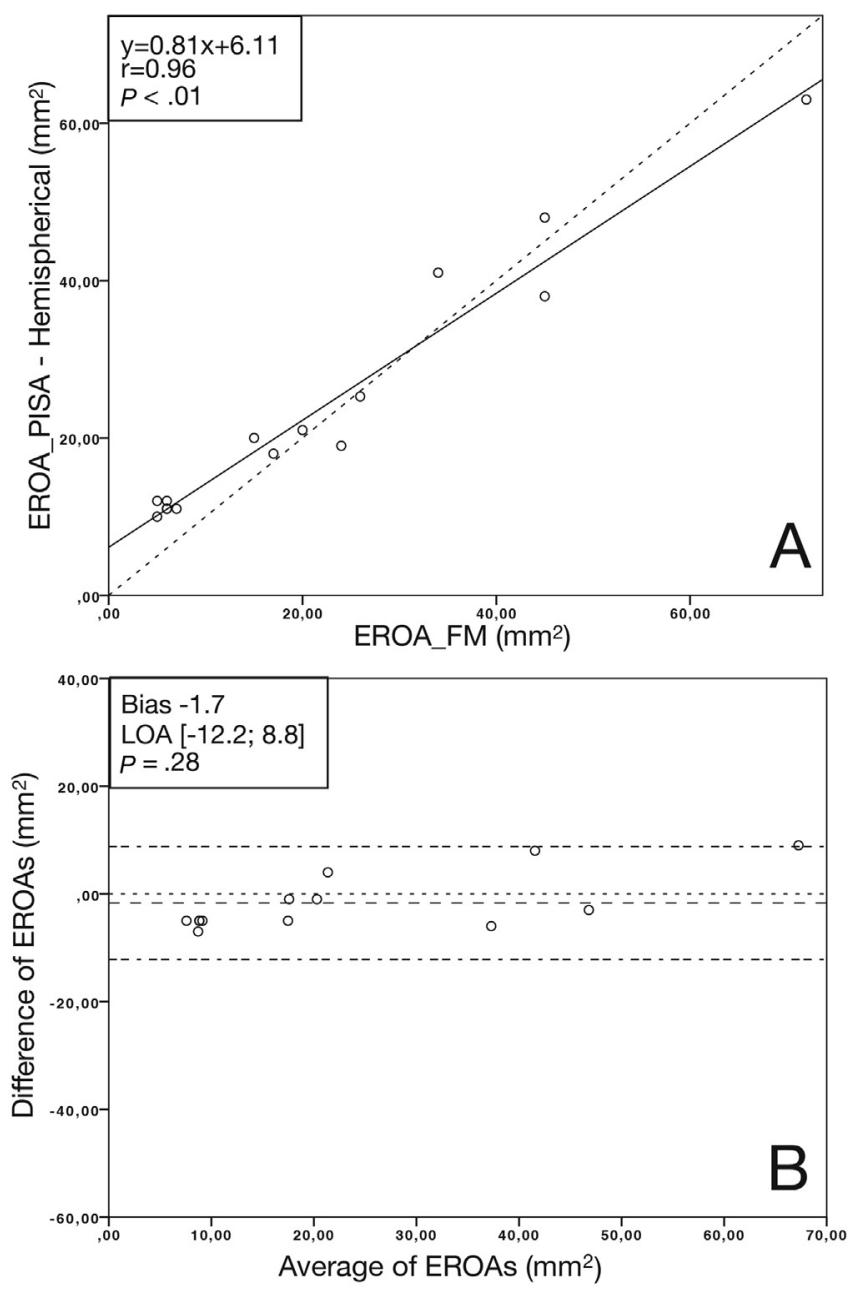

_.... Identity line __ Regression line __-- Bias _...... Limits of agreement

Figure 3 In vitro acquisition of a central MR mimicked in a bioprosthesis and quantified using the traditional PISA assumption. (A) Linear regression analysis of the EROA_PISA and EROA_FM. (B) Bland-Altman analysis of differences between the EROA_PISA and EROA FM.

correlated well with the EROA_2DQV $(r=0.95, P<.01)$, with no significant underestimation (bias, $3.5 \pm 20.8 \mathrm{~mm}^{2}, P=.25$ ) and no significant absolute error $\left(8.4 \pm 13.8 \mathrm{~mm}^{2}, P=.26\right)$. The hemiellipsoidal assumption also had an excellent correlation $(r=0.93, P<.01)$, with no significant underestimation (bias, $-7.3 \pm 23.6 \mathrm{~mm}^{2}, P=.05$ ) and an absolute error of $11.4 \pm 15.5 \mathrm{~mm}^{2}(P=.05)$.

In the setting of a multiple-jet MR, the hemispherical PISA underestimated the EROA_PISA by $22.5 \% \pm 13.6 \%$ compared with the EROA_2DQV. The error was reduced by considering both convergence zones and applying the double-hemispherical assumption $(10.4 \% \pm 11.6 \%)$.

The interobserver and intraobserver variabilities for EROA measurements with the modified PISA methods are reported in Table 4.

\section{DISCUSSION}

The aim of the study was to evaluate the precision of the PISA method in specific situations. The conclusions were that (1) the classical PISA method underestimated the RVol for an oblong orifice, but a correction in the formula taking into account the width of the convergence zone allows for a more reliable evaluation; and (2) the PISA method was reliable for a single round orifice and convergence zone, while in the case of an MR through double regurgitant orifices, both convergence zones must be considered in order to avoid an underestimation.

With the development of transcatheter treatments of secondary $\mathrm{MR}$, the precise assessment of the RVol is of crucial importance. European and American guidelines consider the PISA method as the reference for MR quantification and point out that it should be performed whenever possible. ${ }^{20,21}$ As the COAPT and Mitra-FR trials showed, the benefit of invasive procedures is directly linked to the degree of regurgitation: among other parameters, an EROA $>40 \mathrm{~mm}^{2}$ was associated with an improvement in survival in the COAPT trial, whereas smaller degrees of regurgitation did not demonstrate any benefit from interventional procedures. ${ }^{22}$ This is also supported by the latest American guidelines, that considered the $20 \mathrm{~mm}^{2}$ cutoff not specific enough for severe MR in secondary MR, whereas a $40 \mathrm{~mm}^{2}$ cutoff should be considered as more specific, although lacking sensitivity. ${ }^{3}$ Grayburn et al. ${ }^{23}$ also developed the concept of disproportionate MR, showing that the degree of secondary MR could be proportionate or disproportionate when compared with 

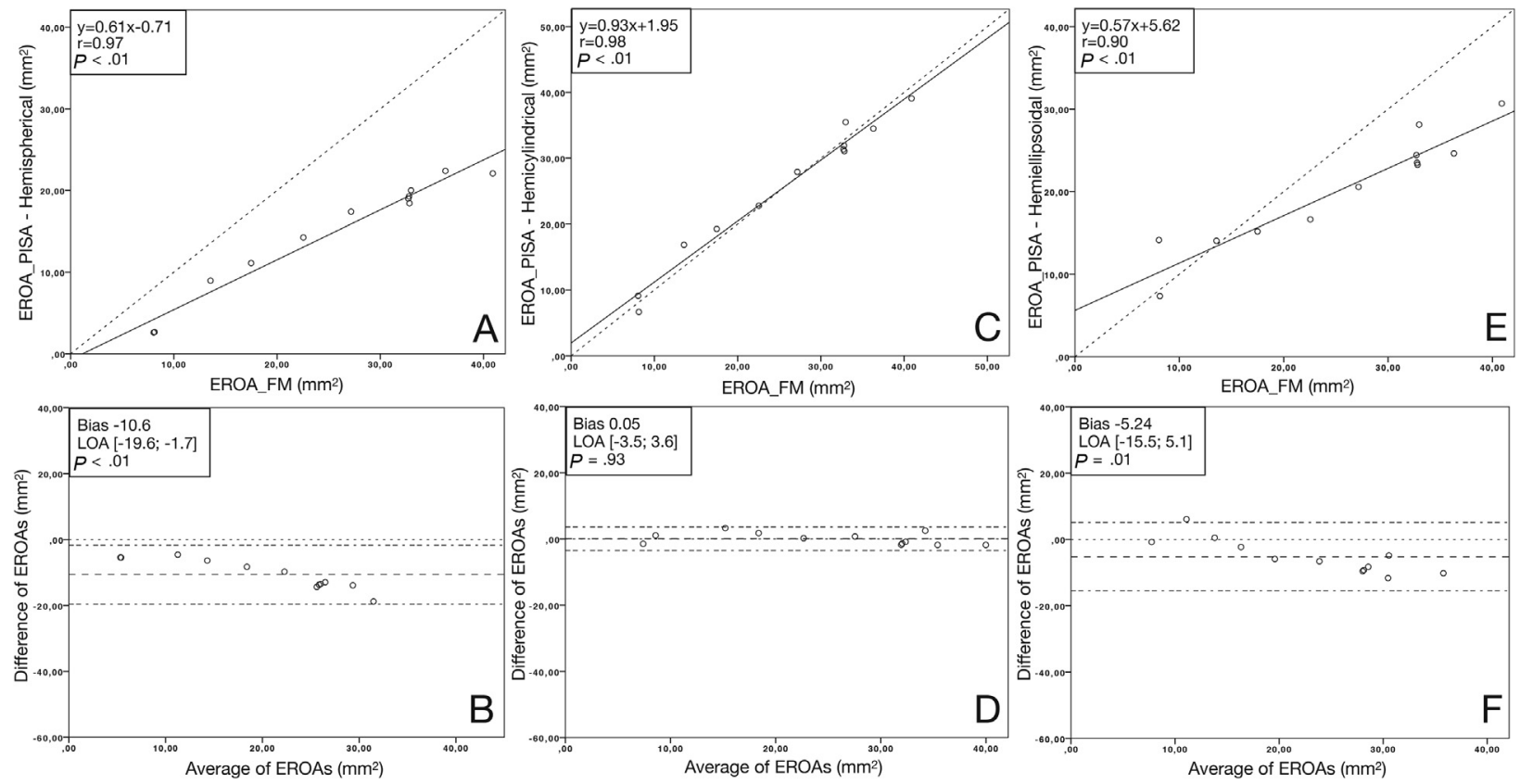

.... Identity line _ Regression line -.-- Bias ...... Limits of agreement

Figure 4 In vitro acquisition of an oblong MR mimicked in a bioprosthesis and quantified using three PISAs assumptions (hemispherical PISA, hemicylindrical PISA, and hemiellipsoidal PISA). (A, C, E) Linear regression analysis of the EROA_PISA and EROA_FM. (B, D, F) Bland-Altman analysis of differences between the EROA_PISA and EROA_FM.
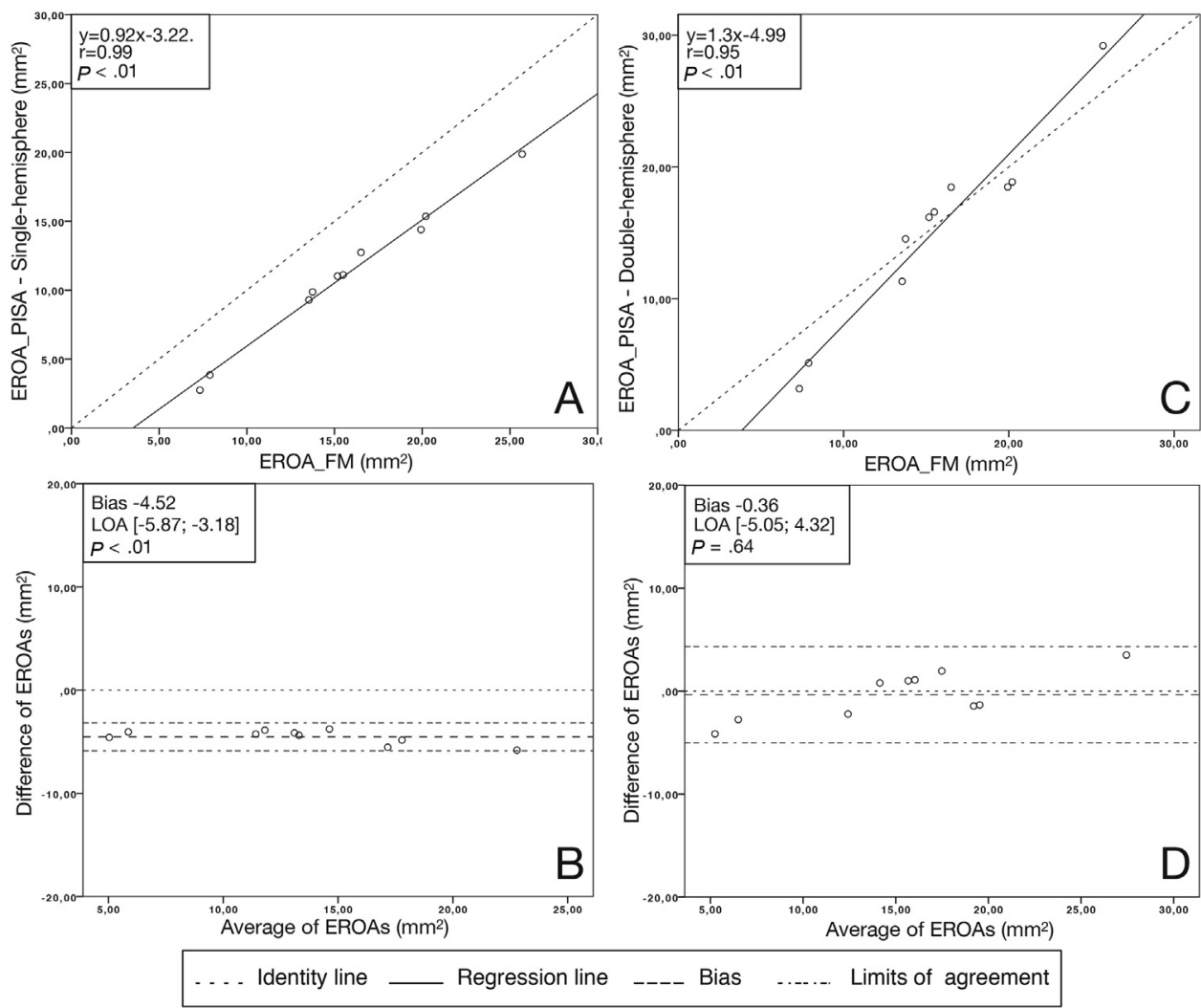

Figure 5 In vitro acquisition of double-jet MR mimicked in an anatomically shaped MV and quantified using two PISAs assumptions (single hemispherical PISA and double hemispherical PISAs). (A, C) Linear regression analysis of the EROA_PISA and EROA_FM. (B, D) Bland-Altman analysis of differences between the EROA_PISA and EROA_FM. 
Table 3 Average values from in vivo investigations of RVol and EROA given by PISA method and 2DQV measurements

\begin{tabular}{|c|c|c|c|c|c|c|}
\hline PISA assumption & EROA_2DQV & EROA_PISA & $P$ value & RVol_2DQV & RVol_PISA & $P$ value \\
\hline \multicolumn{7}{|l|}{ Oblong MR } \\
\hline Hemispherical & $57.6 \pm 21.5$ & $32.6 \pm 19.8$ & .01 & $62.8 \pm 19.8$ & $44.1 \pm 22.1$ & $<.01$ \\
\hline Hemicylindrical & $57.6 \pm 21.5$ & $47.4 \pm 23.7$ & .26 & $62.8 \pm 19.8$ & $63.8 \pm 24.7$ & .83 \\
\hline Hemiellipsoidal & $57.6 \pm 21.5$ & $36.7 \pm 17.3$ & .05 & $62.8 \pm 19.8$ & $49.2 \pm 11.6$ & $<.01$ \\
\hline \multicolumn{7}{|l|}{ Double-jet MR } \\
\hline Hemispherical & $42.7 \pm 18.8$ & $30.8 \pm 22.3$ & - & $71.8 \pm 37.8$ & $49.7 \pm 43.1$ & - \\
\hline Double hemispherical & $42.7 \pm 18.8$ & $38.0 \pm 24.7$ & - & $71.8 \pm 37.8$ & $60.9 \pm 48.6$ & - \\
\hline
\end{tabular}

Data are shown as mean $\pm \mathrm{SD}$. EROA is in units of $\mathrm{mm}^{2}$, and RVol is in units of $\mathrm{mL}$.

the level of LV dysfunction. Therefore, patients with disproportionate MR could theoretically have more benefits from catheter-based interventions. Consequently, a precise evaluation of MR is crucial for diagnosis and optimal treatment.

The underestimation of the RVol in secondary MR is mainly the consequence of the crescent shape of the regurgitant orifice area. In previous studies, as the short radius was used in the classical PISA calculation, the underestimation of the EROA could reach up to 24\%. ${ }^{24}$ Among the tools to correct this underestimation, 3D echocardiography appears to be a good choice, as it allows a global visualization and measurement of the regurgitant orifice area. Yosefy et al. ${ }^{25}$ used a modified hemielliptical formula using 3D data, which totally corrected a 29\% underestimation obtained by the classical PISA method. ${ }^{25}$ More recently, direct measurement of the 3D vena contracta was proposed as an alternative, increasing the measurement of the EROA by $27 \%$ and improving the accuracy of MR grading by eliminating geometric and flow assumptions. ${ }^{26}$ However, 3D echocardiography is also subject to pitfalls: color Doppler blooming, limited temporal and spatial resolution, and time-consuming offline analysis. Recent evolutions, such as the 3D field optimization method algorithm, did not significantly outperform the classical 2D PISA. ${ }^{27}$

Considering these shortcomings, we developed in vitro a 2D multiplane method, based on the measurement of both the height and the width of the PISA. Interestingly, in the oblong regurgitant orifice, an actual in vitro RVol_FM of $40 \mathrm{~mm}^{2}$, which is the threshold for severe primary regurgitation, was calculated with the classical PISA method as $20 \mathrm{~mm}^{2}$, the threshold for severe secondary regurgitation. ${ }^{21,28} \mathrm{An}$ improvement in the measurement method would potentially allow a standardization of the cutoff for severe MR.

The in vivo evaluation first included a comprehensive evaluation of the regurgitation mechanism and jet orientation, in the short- and longaxis views. The most relevant formula could then be chosen between an oblong one jet (hemispheric or hemicylindrical) or two separated jets. The results obtained with the hemicylindrical assumption were very positive, both in the in vitro and in vivo experiments. With the RVol obtained with the flowmeter as reference, the hemicylindrical method
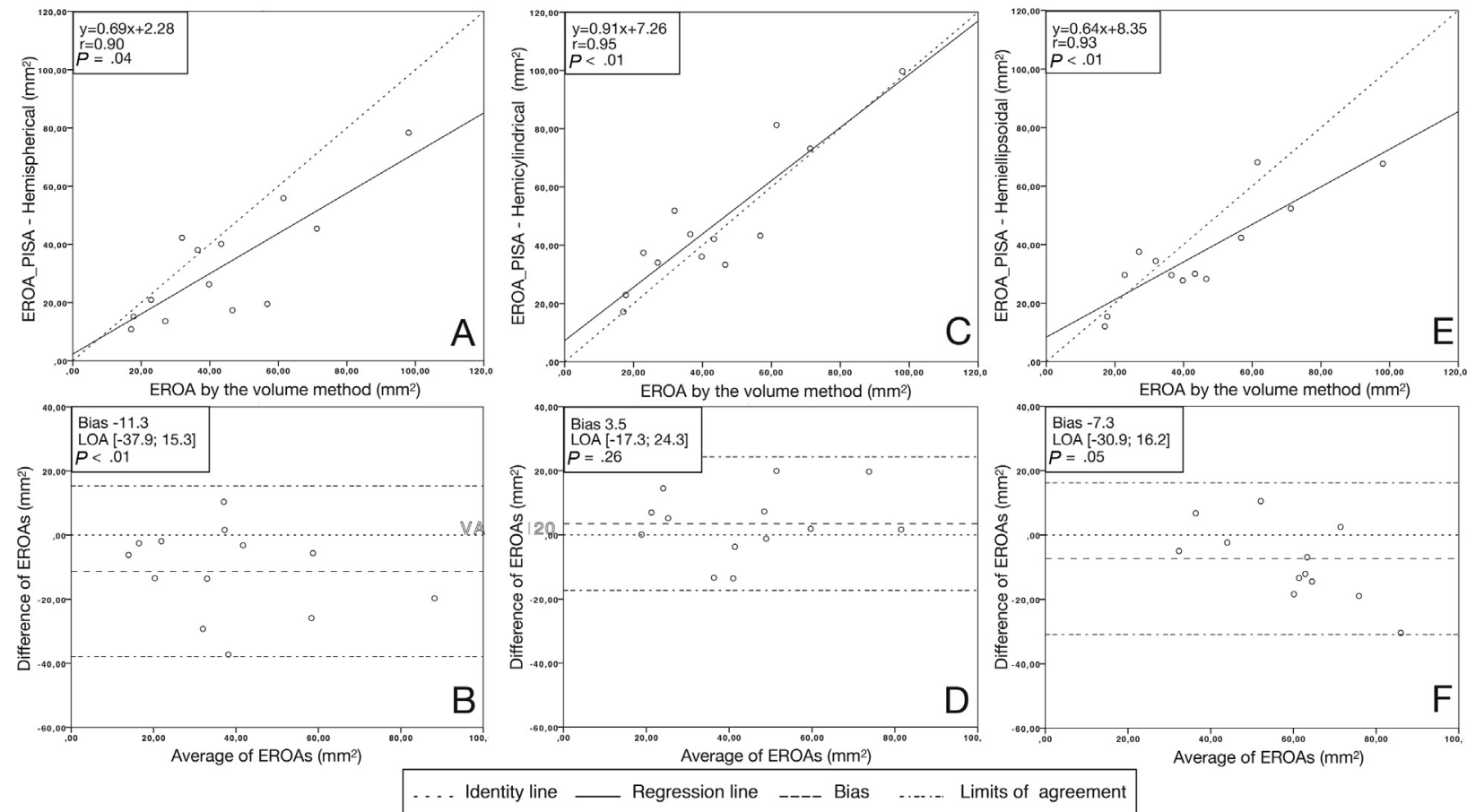

Figure 6 In vivo acquisition in a patient with oblong MR and quantified using three PISA assumptions (hemispherical PISA, hemicylindrical PISA, and hemiellipsoidal PISA). (A, C, E) Linear regression analysis of the EROA_PISA and EROA_2DQV. (B, D, F) BlandAltman analysis of differences between the EROA_PISA and EROA_2DQV. 
Table 4 Interobserver and intraobserver variabilities

\begin{tabular}{|c|c|c|c|c|c|}
\hline \multirow[b]{2}{*}{$\begin{array}{l}\text { EROA calculation } \\
\text { method }\end{array}$} & \multicolumn{3}{|c|}{ Interobserver variability $(n=10)$} & \multicolumn{2}{|c|}{ Intraobserver variability $(n=4)$} \\
\hline & $\begin{array}{l}\text { Variability } \\
\text { coefficient, \% }\end{array}$ & $\begin{array}{l}\text { Correlation } \\
\text { coefficient }\end{array}$ & $\begin{array}{c}\text { Bland-Altman } \\
\text { bias } \pm 1.96 * \mathrm{SD}, \mathrm{mm}^{2}\end{array}$ & $\begin{array}{c}\text { Variability } \\
\text { coefficient, } \%\end{array}$ & $\begin{array}{c}\text { Bland-Altman } \\
\text { bias } \pm 1.96 * \mathrm{SD}, \mathrm{mm}^{2}\end{array}$ \\
\hline $\begin{array}{l}\text { EROA_PISA hemispherical } \\
\text { assumption }\end{array}$ & 1.0 & $r^{2}=0.98(P<.001)$ & $0.3 \pm 4.3(P=.66)$ & 1.3 & $1.3 \pm 6.4(P=.47)$ \\
\hline $\begin{array}{l}\text { EROA_PISA hemicylindrical } \\
\text { assumption }\end{array}$ & 1.6 & $r^{2}=0.98(P<.001)$ & $2.1 \pm 5.6(P=.06)$ & 2.3 & $2.7 \pm 8.1(P=.28)$ \\
\hline $\begin{array}{l}\text { EROA_PISA hemiellipsoidal } \\
\text { assumption }\end{array}$ & 2.7 & $r^{2}=0.91(P<.001)$ & $-1.2 \pm 10.4(P=.53)$ & 2.2 & $2.5 \pm 5.6(P=.17)$ \\
\hline
\end{tabular}

allowed a close to perfect correction in vitro, with a slope of 0.93 for a nonsignificant bias of $-0.2 \mathrm{~mm}^{2}$. The in vivo results were consistent, with an improvement of correlation slope from 0.69 to 0.91 , with no significant bias. Moreover, the modified PISA calculation required only one additional echocardiographic measurement-the width of the regurgitant jet in the apical two-chamber view-so that the method would not extend the exam time and could even be implemented in ultrasound devices, without long postprocessing times. For comparison, offline analysis of 3D PISA can last up to 45 minutes. ${ }^{29}$ Although based on geometric assumptions, our method would allow for a reliable, reproducible, and easy to apply method without postprocessing.

Currently, in the case of multiple jets, it is not recommended to add the vena contracta and the PISA assumption is not considered valid. ${ }^{21}$ Recently, the use of combined 2D formulas (classical PISA for a single jet, partial hemicylinder for fused PISAs, full hemicylinder for nonfused PISAs) was performed as well as the 3D EROA in vitro compared with the quantitation by flowmeter. ${ }^{10}$ Conversely, in our experiment, we quantified two uneven nonfused jets, in rigid plates and in a physiologic MV. In both situations, the addition of the RVol_PISA was validated with respect to the flowmeter. The correction formula led to an increase in the slope of the correlation (from 0.9 to 1.3 ), which made the error more sensitive to the EROA. However, with the correlation line crossing the identity line around $17 \mathrm{~mm}^{2}$, the error after correction for the degrees of MR encountered in clinical conditions, the error was always lower than $5 \mathrm{~mm}^{2}$, which is lower than the error for the PISA method for a central orifice in a bioprosthesis. Moreover, considering a regurgitation with a VTI of $150 \mathrm{~cm}$, the error in the EROA would range from 0 for moderate regurgitations to $5 \mathrm{~mm}^{2}$ for severe regurgitations, which seems acceptable in clinical practice. Although the number of patients with two separated jets was relatively low in the in vivo confirmation, the results obtained with the addition of the two EROAs were encouraging. We did not have 3D echocardiography at our disposal in this study, but it could be of use to visualize that the two jets are clearly separated, rather than an oblong jet only visualized at the commissures. Therefore, the summation of the RVol and thus of the EROA seems to be an acceptable method to quantify two even or uneven nonfused jets.

\section{Study Limitations}

An inherent pitfall with the PISA method is the assumption that the flow is constant throughout the systole, whereas the radius is larger during early and late systole in functional regurgitation. ${ }^{10}$ The method does not take into account the variations of the flow during the cycle. Like in clinical practice, we chose to measure the PISA radius at midsystole, corresponding to the peak velocity measured with continuous-wave Doppler.
In our in vivo study, the sample of patients was relatively small. However, its purpose was only to test the feasibility of the method. Therefore, its applicability and potential new thresholds should be tested in larger-scale trials. As patients were included in a retrospective way, cardiac magnetic resonance and $3 \mathrm{D}$ volumes were not available in all patients for MR quantification. However, the 2D quantitative volumetric method is recommended as a valid method in the American Society of Echocardiography guidelines and is an efficient way to overcome the MR geometry, especially in experienced centers. ${ }^{20}$

\section{CONCLUSION}

The PISA method was investigated in this study by examining several configurations of regurgitant orifices in a controlled and physiologic environment. For an MR with an oblong regurgitant orifice, the hemicylindrical assumption of PISA allowed for a better quantification of the RVol than the conventional hemispheric assumption. In the case of an MR with several regurgitant orifices, the quantification assumption should take into account all the regurgitant orifices and not only the largest one.

All methods of quantification of mitral insufficiency proposed in this study require simple measurements and could therefore be easily used in clinical practice and implemented on ultrasound machines. More precise evaluation is required in the era of catheter-based interventional correction of secondary MR, as the expected benefits are directly dependent on the RVol. Larger clinical studies are required to evaluate these new approaches to MR quantification.

\section{ACKNOWLEDGEMENTS}

We thank Pr. Philippe Pibarot for his useful and relevant comments during the conception of this study.

\section{SUPPLEMENTARY DATA}

Supplementary data to this article can be found online at https://doi. org/10.1016/j.echo.2020.03.008.

\section{REFERENCES}

1. Nkomo VT, Gardin JM, Skelton TN, Gottdiener JS, Scott CG, Enriquez Sarano M. Burden of valvular heart diseases: a population-based study. Lancet 2006;368:1005-11. 
2. Thavendiranathan P, Phelan D, Collier P, Thomas JD, Flamm SD, Marwick TH. Quantitative assessment of mitral regurgitation: how best to do it. JACC Cardiovasc Imaging 2012;5:1161-75.

3. Nishimura RA, Otto CM, Bonow RO, Carabello BA, Erwin JP, Fleisher LA, et al. 2017 AHA/ACC focused update of the 2014 AHA/ACC guideline for the management of patients with valvular heart disease: a report of the American College of Cardiology/American Heart Association task force on clinical practice guidelines. Circulation 2017;135:e1159-95.

4. Baumgartner H, Falk V, Bax JJ, De Bonis M, Hamm C, Holm PJ, et al. 2017 ESC/EACTS Guidelines for the management of valvular heart disease. Eur Heart J 2017;38:2739-91.

5. Mack MJ, Abraham WT, Lindenfeld J, Bolling SF, Feldman TE, Grayburn PA, et al. Cardiovascular outcomes assessment of the MitraClip in patients with heart failure and secondary mitral regurgitation: design and rationale of the COAPT trial. Am Heart J 2018;205:1-11.

6. Obadia J-F, Messika-Zeitoun D, Leurent G, Iung B, Bonnet G, Piriou N, et al. Percutaneous repair or medical treatment for secondary mitral regurgitation. N Engl J Med 2018;379:2297-306.

7. Enriquez-Sarano M, Miller FA, Hayes SN, Bailey KR, Tajik AJ, Seward JB. Effective mitral regurgitant orifice area: clinical use and pitfalls of the proximal isovelocity surface area method. I Am Coll Cardiol 1995;25:703-9.

8. Utsunomiya T, Doshi R, Patel D, Mehta K, Nguyen D, Henry WL, et al. Calculation of volume flow rate by the proximal isovelocity surface area method: simplified approach using color Doppler zero baseline shift. J Am Coll Cardiol 1993;22:277-82.

9. Lin BA, Forouhar AS, Pahlevan NM, Anastassiou CA, Grayburn PA, Thomas JD, et al. Color Doppler jet area overestimates regurgitant volume when multiple jets are present. J Am Soc Echocardiogr 2010;23: 993-1000.

10. Zürcher F, Brugger N, Jahren SE, de Marchi SF, Seiler C. Quantification of multiple mitral regurgitant jets: an in vitro validation study comparing twoand three-dimensional proximal isovelocity surface area methods. J Am Soc Echocardiogr 2017;30:511-21.

11. Hyodo E, Iwata S, Tugcu A, Arai K, Shimada K, Muro T, et al. Direct measure ment of multiple vena contracta areas for assessing the severity of mitral regurgitation using 3D TEE. JACC Cardiovasc Imaging 2012;5:669-76.

12. Iwakura $\mathrm{K}$, Ito H, Kawano S, Okamura A, Kurotobi T, Date M, et al. Comparison of orifice area by transthoracic three-dimensional Doppler echocardiography versus proximal isovelocity surface area (PISA) method for assessment of mitral regurgitation. Am J Cardiol 2006;97:1630-7.

13. Jang JY, Kang J-W, Yang DH, Lee S, Sun BJ, Kim D-H, et al. Impact of a geometric correction for proximal flow constraint on the assessment of mitral regurgitation severity using the proximal flow convergence method. J Cardiovasc Ultrasound 2018;26:33-9.

14. Pu M, Vandervoort PM, Greenberg NL, Powell KA, Griffin BP, Thomas JD Impact of wall constraint on velocity distribution in proximal flow convergence zone. Implications for color Doppler quantification of mitral regur gitation. J Am Coll Cardiol 1996;27:706-13.

15. Buck T, Jansen CHP, Yoganathan AP, Levine RA, Handschumacher MD Hemisphere versus hemiellipse: when is each most accurate for proximal isovelocity calculation of regurgitant flows. J Am Coll Cardiol 1998;31: 385.
16. Matsumura Y, Saracino G, Sugioka K, Tran H, Greenberg NL, Wada N, et al. Determination of regurgitant orifice area with the use of a new three-dimensional flow convergence geometric assumption in functional mitral regurgitation. J Am Soc Echocardiogr 2008;21:1251-6.

17. Tanné D, Bertrand E, Kadem L, Pibarot P, Rieu R. Assessment of left heart and pulmonary circulation flow dynamics by a new pulsed mock circulatory system. Experi Fluids 2010;48:837-50.

18. Alfieri O, Maisano F, De Bonis M, Stefano PL, Torracca L, Oppizzi M, et al. The double-orifice technique in mitral valve repair: a simple solution for complex problems. J Thorac Cardiovasc Surg 2001;122:674-81.

19. Lawden DF. Elliptic Functions and Applications. New York: Springer-Verlag; 1989.

20. Zoghbi WA, Adams D, Bonow RO, Enriquez-Sarano M, Foster E, Grayburn PA, et al. Recommendations for noninvasive evaluation of native valvular regurgitation. J Am Soc Echocardiogr 2017;30:303-71.

21. Lancellotti P, Tribouilloy C, Hagendorff A, Popescu BA, Edvardsen T, Pierard LA, et al. Recommendations for the echocardiographic assessment of native valvular regurgitation: an executive summary from the European Association of Cardiovascular Imaging. Eur Heart J Cardiovasc Imaging 2013;14 611-44.

22. Stone GW, Lindenfeld J, Abraham WT, Kar S, Lim DS, Mishell JM, et al. Transcatheter mitral-valve repair in patients with heart failure. N Engl J Med 2018;379:2307-18.

23. Grayburn PA, Sannino A, Packer M. Proportionate and disproportionate functional mitral regurgitation. JACC Cardiovasc Imaging 2019;12: 353-62.

24. Matsumura Y, Fukuda S, Tran H, Greenberg NL, Agler DA, Wada N, et al. Geometry of the proximal isovelocity surface area in mitral regurgitation by 3-dimensional color Doppler echocardiography: difference between functional mitral regurgitation and prolapse regurgitation. Am Heart J 2008; 155:231-8.

25. Yosefy C, Levine RA, Solis J, Vaturi M, Handschumacher MD, Hung J. Proximal flow convergence region as assessed by real-time 3 dimensional echocardiography: challenging the hemispheric assumption. J Am Soc Echocardiogr 2007;20:389-96.

26. Zeng X, Levine RA, Hua L, Morris EL, Kang Y, Flaherty M, et al. Diagnostic value of vena contracta area in the quantification of mitral regurgitation severity by color Doppler 3D echocardiography. Circ Cardiovasc Imaging 2011:4:506-13.

27. Pierce EL, Rabbah JPM, Thiele K, Wei Q, Vidakovic B, Jensen MO, et al Three-dimensional field optimization method: gold-standard validation of a novel color Doppler method for quantifying mitral regurgitation. J Am Soc Echocardiogr 2016;29:917-25.

28. Grigioni F, Enriquez-Sarano M, Zehr KJ, Bailey KR, Tajik AJ. Ischemic mitral regurgitation: long-term outcome and prognostic implications with quantitative Doppler assessment. Circulation 2001;103:1759-64.

29. Brugger N, Wustmann K, Hürzeler M, Wahl A, de Marchi SF, Steck H, et al. Comparison of three-dimensional proximal isovelocity surface area to cardiac magnetic resonance imaging for quantifying mitral regurgitation. Am J Cardiol 2015;115:1130-6.

30. Gharib M, Rambod E, Kheradvar A, Sahn DJ, Dabiri JO. Optimal vortex formation as an index of cardiac health. Proc Natl Acad Sci USA 2006; 103:6305-8. 


\section{Validation of the Anatomically Shaped MV}

Echographic measurements were acquired for several hemodynamics conditions: variation of the mean aortic pressures $(40$ and $100 \mathrm{~mm}$ $\mathrm{Hg}$ ), of the mitral flow volumes $(3,4.5$, and $5.5 \mathrm{~L} / \mathrm{min})$, and of the heart rate $(45$ and $70 \mathrm{bpm})$ and the mitral flow profile (E wave/A wave $=1.5$ ). The measured mean transvalvular pressure gradient was $3 \pm 1 \mathrm{~mm} \mathrm{Hg}$. The vortex formation time defined by Gharib et al. ${ }^{30}$ was calculated to be $T=5.3$, which is within the optimal range of $3.3<T<5.5$, a predictor of a healthy LV. 